\title{
Las publicaciones de los museos sobre sus colecciones. El caso "ediciones digitales"del Museo Castagnino+macro
}

\author{
Alejandra Gabriela Panozzo Zenere \\ Universidad Nacional de Rosario - UNR, Argentina
}

CASE REPORT

\begin{abstract}
Resumen
Los museos producen mensajes para legitimar y desarrollar un relato sobre su colección a través de sus espacios expositivos, actividades educativas, eventos masivos, publicaciones, entre otras opciones. En la actualidad, las piezas gráficas o editoriales se convierten en herramientas que permiten acercarse a las prácticas comunicacionales que operan en este tipo de institución cultural. Por ello, el presente trabajo tiene por objetivo desentrañar algunas transformaciones que se producen en este tipo de dispositivo en el modelo museístico contemporáneo.

Esta exploración articula enfoques teóricos críticos museológicos y estudios de lo comunicacional. En este entrecruzamiento se busca, primeramente, trabajar el uso de este tipo de dispositivos, luego, definir algunos rasgos significativos que cobran las publicaciones en la actualidad a partir de los cruces entre comercial-experiencia-TICs, para confluir en un posible ejemplo de este tipo de propuesta llevada adelante por el museo argentino Castagnino+macro.
\end{abstract}

Palabras-clave

Argentina; Museo Castagnino+macro; Museos; Publicaciones; TICs.

\section{Museum publications on their collections. The "digital editions" case of the Castagnino+macro Museum}

\begin{abstract}
Museums produce messages to legit and develop an essay about its collection through its expositive spaces, educational activities, missives events, publication, among others. In the present, the graphical pieces or editorial becomes in tools that allow getting closer to the communicational practices that take places in this cultural institution. Therefore, the present work has for objective to unravel some transformations that are produced in this kind of device

in the contemporary museum model.

This exploration articulates museological critical theoretical approaches and studies of the communicational. In this crosslinked we look for, first, to work the use of this device, then, to define some significant features that current publications charge from crossings between commercial-experience-ICTs, to come together in a possible example of this type of proposal carried out by the argentine museum Castagnino+Macro.
\end{abstract}

Keywords

Argentina; ICTs; Museo Castagnino+macro; Museum; Publications.

\section{Introducción}

Los museos -de naturaleza dinámica- son instituciones propias del capitalismo, en consecuencia, su desarrollo depende de las variaciones de dicho sistema y de la propia entidad. Según Tony Bennett (1996), este tipo de establecimiento se encuentra dentro de un archipiélago de instituciones de espectáculo que son de control pero no de castigo y, por tanto, más blandas que el sistema carcelario o el hospicio. De ahí que se trate de una institución disciplinadora que comunica de manera diferente a lo largo del tiempo; es decir, en el museo moderno cumplía un rol de instrucción pedagógica, en el museo posmoderno se uniría al entretenimiento, y en el museo contemporáneo se ofrece bajo los anteriores rasgos y acentua su carácter de experiencia. 
Estamos ante un abordaje del museo como medio de comunicación masivo (García Canclini, 2001; Verón, 1992; Huyssen, 2007), aunque también se puede conceptualizar a modo de red de medios -al referenciar los dispositivos comunicacionales propios y ajenos que en el se utilizan-. Se presenta bajo un rol de constructor y emisor de un relato que da a conocer y legitima aquello en lo que se quiere disciplinar a los públicos (Panozzo Zenere, 2018). Este tipo de circunstancias enmarcan el carácter enunciador de esta entidad patrimonial, lo que habilita interrogantes sobre la dimensión de qué comunica y cómo lo hace.

Estamos ante la lectura de las prácticas comunicacionales -exposiciones, publicaciones o plataformas digitalesque se ponen en circulación en los espacios/servicios para desarrollar aspectos que hacen al universo comunicativo de este tipo de establecimiento, pero desde las particularidades que lo configuran como una institución cultural con reglas propias y con una legitimidad específica cimentada en el entramado cultural. Ante esta posibilidad de opciones, nuestro trabajo se detiene brevemente en las etapas de creación, producción, distribución y consumo (Getino, 1995) que se detectan en las publicaciones que se conciben en los museos, para luego ahondar en las diferencias analíticas y estéticas de su utilización por parte de la sede museal para acercarnos a la construcción de los relatos museales.

Las piezas gráficas o editoriales son recursos identitarios que potencian la información -texto e imagen- del acervo, las exposiciones temporales, la historia o la identidad del museo, los objetos museales, sus creadores, entre otras posibilidades. No obstante, es de aclarar que a los fines de esta indagación nos detendremos en aquellas materialidades que son generadas por la sede museal y ponen el acento en su colección. No contemplamos, de esta manera, aquellas producidas por otras instituciones culturales que son ofrecidas en los espacios de consumo del museo, como tampoco otras piezas que se basan en exposiciones temporales, productores artísticos, actores fundacionales, áreas institucionales u otros.

\section{Las publicaciones de los museos, dispositivos comunicacionales}

Dentro del universo de las publicaciones creadas por los museos existe una amplia gama de posibilidades: catálogos, libros, revistas, folletos, CD, entre otras opciones. Estamos en presencia de una diversidad de soportes impresos y digitales que proporcionan un uso comunicacional específico, el cual está íntimamente relacionado con una función instrumental que permite al museo extenderse más allá de sus límites físicos. Se trata de considerarlas desde una técnica determinada y una manera de establecer procesos correspondientes a sus singularidades, que logran un desplazamiento enunciativo del establecimiento y habilitan diferentes posibilidades de interrelación con los públicos. Es decir, la creación de este tipo de piezas gráficas o editoriales está ligada al valor simbólico de este producto para satisfacer diferentes necesidades comunicativas educación, investigación, conservación- y otras específicas. Este proceso comunicacional se distingue de otros, ya que apela a una serie de recursos materiales, humanos y económicos para constituirlas y legitimarlas.

En el caso de las publicaciones de los museos que se detienen en la colección nos ofrecen información sobre el acervo, pero también brindar referencias sobre las piezas, las técnicas, el contexto, las temáticas, los diálogos y las problemáticas con que son elegidas o agrupadas. Estas condiciones se vinculan con la manera de ser producidas -fase asociada al sistema de trabajo (Getino, 1995)-, lo que habilita leer patrones o modelos que construyen procedimientos asociados a la puesta y calidad de cómo se ofrecen o qué brindan a lo largo de sus páginas o puestas digitales. En otras palabras, este dispositivo exterioriza una práctica comunicacional que posibilita al museo cumplir con su función disciplinadora, al constituirse en memoria y registro del relato institucional sobre su patrimonio.

En cuanto a la distribución de las piezas graficas o editoriales encontramos un intercambio particular, ya que estamos en presencia de un proceso que vincula este producto con un consumidor determinado. Aquí, se distingue un conjunto de estrategias, procesos y actividades que se focalizan en una oferta restringida del establecimiento, los espacios expositivos/culturales o actividades puntuales. Esta realidad repercute claramente en la manera en que serán consumidas; es decir, estamos en presencia de un consumo estrechamente asociado a un público cautivo y específico. En definitiva, las condiciones de los procesos -distribución y consumo- presentan un orden de rentabilidad al tener asegurado un consumidor -visitante asiduo del museopero, a su vez, de déficit por circunscribir su ofrecimiento a los espacios de exhibición/servicios o acciones puntuales, y proyectar contenidos delimitados y precisos. 
Lo enunciado hasta aquí posibilita introducirnos en algunas especificidades de las publicaciones, se trata de identificar diferentes usos que se fueron estableciendo por parte del museo a lo largo de su historia institucional. Claro está que no todos los formatos nombrados anteriormente han formado parte de las opciones que se producían en el museo moderno. Dicho de otra manera, prevalecieron, a fines del siglo XVIII y principio del XIX, las presentaciones impresas y, en general, las más utilizadas eran los catálogos o inventarios y los libros institucionales. Mayoritariamente, el uso de este producto estaba asociado a instruir pedagógicamente al público. Irina Podgorny (2009) señala que éstas se habían utilizado en función de crear un dispositivo portátil que presentase un contenido informativo, escritura descriptiva y elección de imágenes icónicas del acervo, con el fin de poner en circulación internacionalmente información sobre las piezas de las colecciones y subsidiar la visita al espacio expositivo. Estas características que presenta el formato permitirían comparar los objetos materiales con las imágenes que exhibían los catálogos, además de aportar datos explicativos sobre el patrimonio. Por ello, durante este período, este tipo de soporte sería herramienta de consulta sobre la información del capital simbólico museal, tanto para el propio personal como para los especialistas, al mismo tiempo que un material instructivo de enseñanza para el público general.

A mediados y fines del siglo XX, las publicaciones comienzan a adquirir aspectos asociados al marketing y el diseño; en sintonía con el tratamiento de todo lo que forma parte de la imagen mediatizada de la sede museal. Estos aspectos comienzan a ser identificados en los museos posmodernos, al delimitar distintas acciones dirigidas a captar la atención de otros visitantes -por ejemplo, los turistas-. Por su parte, estas condiciones se hacen más visibles en los museos contemporáneos, al asociarse en algunos casos a una estrategia netamente de consumo cultural, en donde todo aquello que se produce forma parte de la imagen y la experiencia que se quiere transmitir y, por tanto, se concibe consecuente con ella. Se convierten, de esta manera, las piezas gráficas o editoriales en una posibilidad -que se suma a otras- para que los museos puedan adquirir recursos financieros. Es así que se pasa a identificar a la entidad patrimonial como un agente de venta (Strong, 1983), en tanto, que proyecta lógicas propias de la industria editorial.

Estos dispositivos comunicacionales se une a la inserción de las políticas institucionales que promulga el museo contemporáneo, el cual deja de sostenerse solo con fondos públicos para ser apoyado también por privados. Estamos ante un museo imparable (Laseca, 2016) que se mueve dentro del consenso global y de consumo generalizado para asociarse a la idea de servicio, obligándolo a generar estrategias que posibiliten atraer el patrocinio y el sponsoreo. De este modo, se establece una nueva etapa de negociaciones con las empresas privadas que consideran propicio hacer lobby en estas instituciones culturales o espacios de exhibición para alcanzar una mayor visibilidad (Chin-tao, 2007). En consecuencia, formar parte de los espectáculos y actividades que se ofrecen permitiendo a dichas empresas obtener publicidad en los medios de comunicación que cubren estos eventos para llegar a multitudes o nichos especificos. En esta lógica, las piezas gráficas o editoriales comienzan a portar la marca de las empresas, las cuales serán visualizadas por los espectadores que concurren y consumen la experiencia museal. No obstante, este tipo de decisiones trae aparejado, para la entidad patrimonial, la incidencia de estos actores en las decisiones sobre qué mostrar y cómo mostrarlo. Al respecto, Hans Haacke sostiene

\footnotetext{
Las corporaciones han conseguido efectivamente un veto en los museos, incluso a pesar de que su aporte financiero a menudo solo cubra una fracción de los costos de una exposición. Dependiendo de las circunstancias, estos aportes son deducibles de los impuestos como costos empresariales o un aporte benéfico. Los contribuyentes ordinarios, por lo tanto, están pagando parte de la cuenta. En efecto, sin darse cuenta son patrocinadores inconscientes de políticas empresariales privadas, que, en muchos casos, van en detrimento de su salud y seguridad, el bienestar general, y se hallan en conflicto con su ética personal (1986, p. 9).
}

Este aspecto -la lógica competitiva y comercial- es parte central del carácter que adquiere el museo en la contemporaneidad, lo cual produce transformaciones sustanciales en los formatos, los procesos y los usos de las publicaciones que ellos producen. Estas, ya no solo deben brindan información sobre las colecciones museo moderno- sino que también, por ejemplo, diferencian al establecimiento de otras instituciones similares o permiten identificar a sus auspiciantes - museo posmoderno y contemporáneo-. No obstante, en la actualidad, no se trata del único cambio que adquiere este tipo de formato, aparecen otros modos asociados con la posibilidad de experimentación en respuesta a los fines que promulga la sede contemporánea. Este tipo de estrategia habilita abandonar la idea de museo como simple guardián de musas para convertirse en espacios de 
consumo, entretenimiento y experimentación que ofrecen propuestas atractivas e instancias de participación con/para los visitantes.

\section{Las publicaciones de los museos como posibilidades de lo experiencial}

Los museos del siglo XXI priorizan a los públicos siguiendo la lógica del sistema capitalista contemporáneo, lo cual implica diversificar su programación y sus espacios en una gama de experiencias -comprar, divertirse, aprender, experimentar- y promover otros modos de interrelación con los visitantes, para competir o diferenciarse de otros lugares que también ofrecen propuestas unidas a la experimentación, al ocio y al consumo. Este enfoque exige al museo innovar y originar una experiencia que une

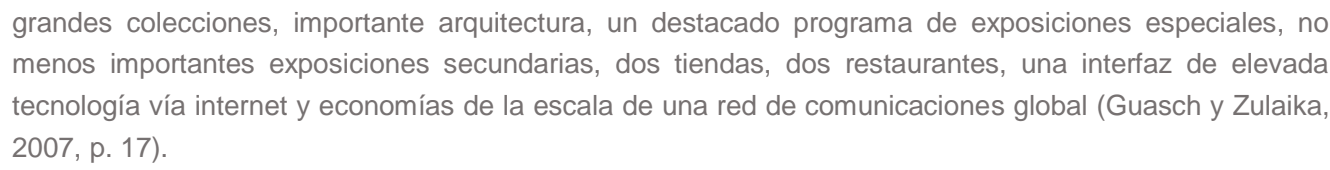

Asimismo, para llevar adelante estas dinamicas institucionales es necesario tener presente los intereses, necesidades y gustos de los visitantes que recorren sus espacios, consumen sus servicios o disfrutan de las actividades. John Flak y Lynn Dierking (1992) sostienen que los individuos en cada una de sus visitas al museo construyen una vivencia subjetiva única e irrepetible, que resulta de la interacción de tres componentes: el físico, el personal y el social. Esto supone que las sedes museales sean experimentadas a través de diferentes acciones o episodios por parte de los visitantes, en donde entran en juego las piezas de las colecciones que son ofrecidas en las exposiciones anuales o temporales, las actividades educativas o los eventos culturales que permiten distintas instancias interactivas y participación, entre otras posibilidades. En esta línea, podemos mencionar la experiencia que conlleva el uso de los dispositivos comunicacionales que ofrece la entidad, los cuales cobran un papel específico en la culminación de la experiencia del visitante al transitar, disfrutar o consumir de estas propuestas (Dewey, 2008).

Siguiendo esta línea, podemos detenernos en algunas particularidades que habilitan las publicaciones de los museos sobre las colecciones. Estos soportes continúan siendo un vehículo de comunicación y educación que transmite el relato institucional sobre el acervo; pero, además, pueden ofrecerse a modo de un dispositivo de mercadeo abrevando en los intereses de privados y de la propia entidad. Sin embargo, destacamos que tambien se convierten en una herramienta que posibilita la condición de un museo amplificado (Parra, 2015). Esta última conceptualización deriva de un seminario brindado en el Museo de Bellas Artes de Santiago de Chile por el curador Cuauhtémoc Medina, quien brindaría nuevas configuraciones y usos de este dispositivo. Entre las nuevas disposiciones reconoce:

- Publicación institucional: productos editoriales que implican un valioso trabajo de investigación, edición, selección de imágenes, adquisición de derechos de reproducción, continuidad con el diseño institucional, por citar algunas características.

- Publicación precoz: pieza gráfica que no es proyectada ni mediada por el profesional editorial o el curador de la exposición.

- Publicación emergente: pieza gráfica que se realiza días antes del evento y con recursos económicos muy limitados, pero con el objetivo de divulgar actividades dentro de una programación o una muestra.

- Publicación experimental: pieza gráfica sobre exposiciones que lindan con convertirse en parte de la experiencia expositiva. Apelan a una lectura no convencional, o formatos especiales, ya que son parte de la compleja experiencia del arte y en tanto tal, utilizan el mismo lenguaje que la exposición.

- Publicación como continuidad de la curaduría: producto editorial que logra una continuidad entre el museo y el exterior, suma un carácter de portabilidad y cierta experimentalidad. 
De esta manera, cualquiera sea el formato que cobre la publicación, lo que importa es que se vuelva deseable por su contenido y diseño, es decir, que se convierten en objeto fetiche (Parra, 2015). Este dispositivo ya no solo es entendido en términos de un objeto físico, sino que transforma su fisonomía puede convertirse en un objeto de culto que presenta un contenido específico y una estética diferenciadora que lo destaca de las demás piezas gráficas o editoriales. Así, se ofrece como una mercancía que puede ser adquirida por todos visitantes. De esta manera, las publicaciones se proyectan como una experiencia portátil que prolonga el recorrido expositivo, y adquieren un valor objetual propio.

Para cumplir con esta tarea es fundamental generar en la estructura institucional un área específica -área o departamento editorial- que trabaje de manera coordinada junto con los diferentes departamentos del establecimiento -diseño, comunicación, investigación- para atender las distintas tareas que conlleva la creación y la producción de este tipo de dispositivos comunicacionales. De allí que el área debe ser capaz de comprender y transmitir la política institucional, las identidades curatoriales, entre otras.

Estas condiciones que adquieren las publicaciones están íntimamente unidas a atender las expectativas de los públicos que visitan este tipo de institución cultural. Además, habilitan la posibilidad de convertirse en instancias vivenciales o de reflexión crítica, en donde se busca que el visitante deje de ser un simple espectador para convertirse en parte activa de la experiencia museal. Es decir, las piezas gráficas o editoriales se separan del paradigma de producto estandarizado para que los sujetos se conviertan, a través de diferentes propuestas, en parte esencial de la producción cultural. De esta manera, se busca constribuir a una dinámica museal que no solo aplique lógicas comerciales sino también que ofresca propuestas vinculadas a la museología participativa y la construcción de pensamiento crítico (Pérez Ruiz, 2008).

Para cumplir con los aspectos mencionados podemos referenciar algunas de las transformaciones que posibilita el uso de las TICs por parte de los museos. La irrupción de estas formas de comunicación, en opinión de Carlos Scolari (2008), se diferencian de las tradicionales mediante los siguientes aspectos: transformación tecnológica (digitalización), configuración muchos-a-muchos (reticularidad), participación activa de los usuarios (interactividad), convergencia de medios y lenguaje (multimedialidad) y estructuras textuales no secuenciales (hipertextualidad). En mayor o menor medida se tratan de rasgos diferenciales en la comunicación de los museos y, en algunos casos, de los dispositivos comunicacionales que construyen y emiten se relato. Por esta razón, las publicaciones actuales no son ajenas a los métodos que trae aparejado el uso de estas formas de comunicación, de allí que comiencen a generar propuestas que pueden ser leídas como híbridas. Es decir, las piezas gráficas o editoriales implementan distintos niveles o herramientas de las TICs -digitalización, multimedia, hipertexto- desplegando, así, potencialidades propias del nuevo entorno. En definitiva, las modificaciones que sufren no implican su desaparición sino mutaciones o hibridaciones que establecen un cambio sin igual para este dispositivo; abriendo un abanico de posibilidades de experimentación y participación con diferentes públicos.

A partir de lo mencionado, las publicaciones sobre las colecciones de los museos unen contenido y estética para generar la sensación de estar ante un elemento que complementa la experiencia museal, tal como disfrutar de los espacios-servicios o de interactuar con las piezas del acervo. Pero, además, según las posibilidades e intereses de las sedes museales pueden convertir en herramientas experimentales que activen un conocimiento crítico o instancias participativas con los visitantes. Por consiguiente, la experiencia no solo está presente en el consumo de la publicación, sino también en el uso que se realiza de la misma. La experiencia museal, de esta manera, se culmina o perpetúa según las condiciones - papel o digital- que posibilita cada formato y de las políticas institucionales que se implementan sobre este tipo de dispositivos comunicacionales.

\section{4 "Ediciones digitales" del Museo Castagnino+macro}

El museo Castagnino+macro se encuentra ubicado en la ciudad de Rosario, en la zona sur de la provincia de Santa Fe -área medular de Argentina-. Este museo cuenta con dos sedes, la primera, el Museo de Bellas Artes "Juan B. Castagnino" creado bajo la dinámica del museo moderno que delimitaron, en el territorio argentino, el ser y hacer de los museos de Bellas Artes. Por el contrario, la segunda, el museo de arte contemporáneo de Rosario, se construye como un anexo a veinte cuadras que replica las lógicas que proyecta este tipo de institución cultural en la contemporaneidad. Esta entidad, a lo largo de su historia, ha tenido una importante proliferación de publicaciones que buscaron, según el portal institucional, la divulgación de material de 
investigación sobre el arte argentino y local; alcanzando en el año 2000 más de treinta títulos. Este esfuerzo se sostendría, además, con la constitución de un área específica editorial que trabajaría en vínculo con otros departamentos -comunicación, educación, registro, investigación-. Entre las piezas que podemos mencionar se encuentran, por ejemplo: "Recetas. Las mejores sugerencias para mirar arte contemporáneo" (2011; 2014; 2016), "Colección histórica del Museo Juan B. Castagnino" (2007) o “Arte Argentino Contemporáneo" (2004). Así como propuestas de diferentes artistas de la ciudad y zonas aledañas, tales como Augusto Schiavoni (2005), Rodolfo Elizalde (2008), Emilio Ghilioni (2008), Julio Rayon (2008), Eduardo Seron (2009), Rubén Porta (2010), Noemí Escandel (2013), entre otros.

El Museo Castagnino+macro, durante 2011, comienza a editar "ediciones digitales"; un producto de investigación de la colección que se desprende del trabajo de distintas perspectivas contemporáneas curatoriales de agentes externos a la sede museal. Esta propuesta es construida y ofrecida exclusivamente en formato digital; apelando a los nuevos modos de circulación de la información a partir del uso de las plataformas que habilitan las TICs, lo cual potencia el acceso público a los contenidos al ser consumidos en línea sin costo. Este modelo permite

poner a disposición del interesado un corpus multimedia como registros fotográficos de las obras expuestas, infografías, videos, audios, textos curatoriales y fichas de obras pertenecientes al Castagnino+macro y, a su vez, vincular esta información gracias a opciones hipertextuales que permiten el acceso a material complementario (Castagnino+macro, 2015, s/p)

La construcción general de estas publicaciones, se realiza en una maquetación en InDesign, y luego son exportadas a PDF. Las últimas ediciones amplia su retroalimentación con el portal institucional, por lo cual abandona la concepción estática para cobrar un carácter más ligado a lo multimedia e interactivo. Para ello, se vale de otros recursos y herramientas digitales que aportan otros programas -Mag+Designd, 3D Issue, Glossique generan, no sólo modificaciones en los aspectos visuales y gráficos, sino que también proponen múltiples interrelaciones sensoriales y experimentales. "ediciones digitales" establece, por tanto, diferentes niveles de interactividad para que el público-usuario pueda interiorizarse sobre el acervo según sus necesidades o gustos, pemitiendo al público-usuario contar con diferentes opciones, por ejemplo, acceder a través de un hipervínculo al portal institucional -http://castagninomacro.org/- para ubicar las reproducciones de las obras y, así, obtener una mayor cantidad de datos descriptivos respecto a su catalogación institucional; o utilizar herramientas para escuchar un audio -conferencia sobre Alberto Pedrotti en la edición no 5- ; o hacer zoom sobre las imágenes de las obras para poder acercarse y apreciar sus detalles -presente en todas las ediciones pero optimizadas en las últimas propuestas-.

El primer número lleva el nombre de "\#espacio" (2011), y es creado a partir de la muestra curada por María Eugenia Spinelli, quien había trabajado la idea de espacio museal como sistema que invadía los lugares edilicios del museo con instalaciones, objetos y multimedia del acervo -principalmente, el contemporáneo-. El segundo, "De azares, sueños y ficciones" (2012), surge de la muestra generada por María Elena Lucero que presenta un ensamble de producciones oníricas o metafísicas, junto una carga de invención y fantasía, a partir de manifestaciones visuales de la segunda década del siglo XX hasta comienzo del XXI. El tercero, "Impreso en la Argentina. Recorridos de la gráfica social desde la colección del Museo Castagnino+macro. A 50 años del Gran Premio en Grabado a Antonio Berni en la Bienal de Venecia" (2013), nace de la muestra llevada adelante por Silvia Dolinko, que da cuenta de las continuidades y los cambios en el grabado -temáticas, técnicas y poéticas-, junto con la articulación de los xilocollages de Antonio Berni sobre Juanito Laguna. El cuarto, "Entre siglos. El impulso cosmopolita en Rosario" (2013), es producto de la muestra curada por Laura Malosetti Costa, María de la Paz López Carvajal y Pablo Montini, que compusieron una nueva mirada sobre las colecciones de arte europeo y argentino del siglo XXI. Continúa, "Construcción de un museo" (2015), basado en la exposición llevada adelante por Federico Baeza, Claudia del Río, Leandro Tartaglia y Santiago Villanueva, realizada durante el décimo aniversario del MACRo, que reflexiona sobre un conjunto de interrogantes sobre el rol del museo y sus visitantes. La última edición se trata de "París en el horizonte. La colección de Enrique Astengo" (2016); una exhibición de las piezas del patrimonio donadas por la familia Astengo al patrimonio del Museo Castagnino+macro y al Museo Histórico Provincial “Julio Marc", exhibición organizada por María de la Paz López Carvajal y Pablo Montini. 


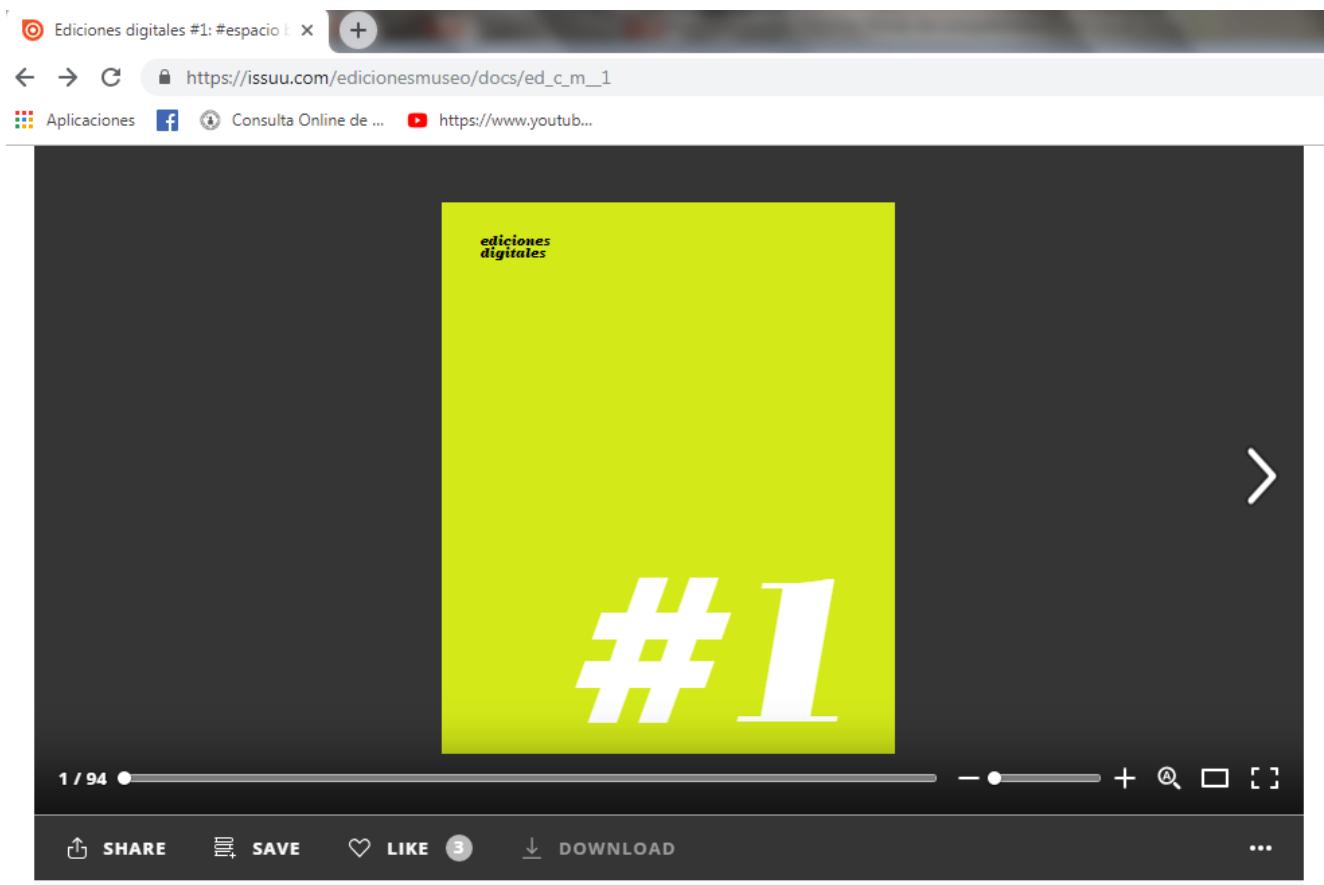

Ediciones digitales \#1: \#espacio

○ isSUU Fresh Publications

의

Image 1. Captura de pantalla de la primera edición de "ediciones digitales"

En cuanto a la fisonomía específica de cada edición, se identifica cada número con una tapa de color saturado que ostenta las palabras "ediciones digitales" en su extremo superior-derecho. Por su parte, en el extremo inferior-izquierdo -en blanco y grande- el símbolo "\#” y el número que corresponde a la publicación. Estas piezas editoriales posibilitan elegir en línea entre diferentes opciones de visualización, entre ellas: libro abierto a una o dos páginas, realizar zoom sobre una zona para ampliar el margen de legibilidad o descargarlo en formato PDF. Todas las propuestas cuentan con textos curatoriales, aunque en "Construcción de un museo" tambíen se ofrece un texto del equipo institucional del Castagnino+macro en conmemoración de los diez años de creación de la sede contemporánea.

En el caso de las imágenes de las obras que se visualizan en estas ediciones, se distingue un tratamiento especial, caracterizado por una gran cantidad y calidad de reproducciones de las piezas de la colección. Dichas imágenes permiten distinguir, por un lado, copias en detalle de las obras con su nombre, año, técnica e ingreso a la colección y, por el otro, su emplazamiento en el espacio físico según la organización que proyecta cada exposición. Ejemplo de este tipo de visualización es "Construcción de un museo" que exhibe el rasgo de las individualidades artísticas que promueve el discurso institucional en referencia a la colección y, a su vez, hace hincapié en sus atributos estéticos que por medio de un enlace con el portal institucional brindan la posibilidad de ampliar la información. Asimismo, proyecta un gran número de fotografías de registro que dan cuenta de la experiencia llevada adelante en las salas expositivas con dichas piezas, es decir, imágenes de las paredes limpias y trabajadas- de las Salas-Pizarron, la inauguración de la muestra, la acción del público con los paneles intervenidos, por citar algunos casos. Por lo tanto, consideramos que el fin de las imágenes es tanto ilustrativo al dar cuenta de la acción de los visitantes a lo largo de la actividad expositiva, pero tambien se convierten en registro o archivo de aquello planteado por los curadores.

Otra condición que percibimos en "ediciones digitales" es que articulan los contenidos presentes en las exposiciones, ejemplo de ello son "Impreso en la Argentina", "Entre siglos" y "París en el horizonte", además, de sumar datos e información de los registros temporales y contextuales para leer el acervo. Por el contrario, "\#espacio", "De azares, sueños y ficciones" y "Construcción de un museo" se detienen en especificidades de lo artístico y lo cultural que deviene de las piezas estéticas elegidas del acervo. El conjunto de estas propuestas editoriales se transforma en un material de consulta para los diferentes públicos luego de realizado el recorrido 
físico por la muestra plástica, lo que permite añadir detalles a las obras o acercarse a los distintos argumentos que comprenden las problemáticas bajo las que fueron agrupadas las piezas de la colección.
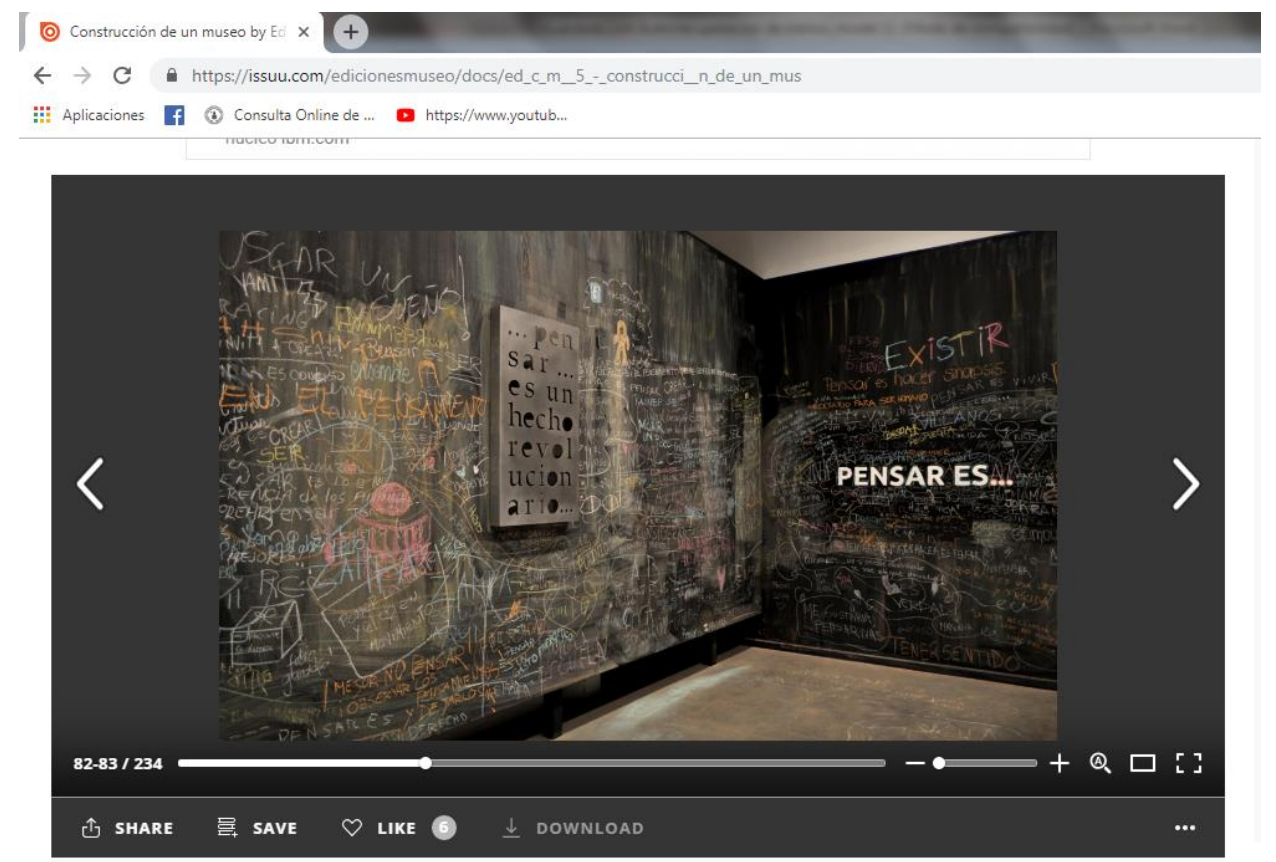

Construcción de un museo

Image 2. Captura de pantalla de una Sala-Pizarrón del quinto número de "ediciones digitales"

Cualquiera de ellas permite intuir que estamos ante un modelo de publicación que se convierte en un producto renovador, ya sea por su accesibilidad a los públicos, los recursos en cuanto al diseño editorial, identificación de la identidad (marca) del museo, la incorporación de tecnología, el bajo costo o la visibilidad de sponsors, así como también una mejor y mayor calidad y cantidad de imágenes -aspecto central en las publicaciones de los museos de arte-. En otras palabras, estas propuestas tienen un formato novedoso que difieren no solo en su constitución y soporte, sino también en las posibilidades que abre para con las obras, los contenidos y el uso de los recursos en línea. Se suma, además, que los textos buscan indagar y reflexionar sobre diferentes aspectos estéticos y contextuales del acervo o a las especificidades del arte desde narrativas distintas con la que se identifica a la sede museal. Asimismo, queremos señalar que el formato digital habilita mayores niveles de interacción con los públicos que el generado por la publicación en papel. No obstante, en el caso de las publicaciones en línea intuimos que aún están siendo direccionadas a un público cautivo, ávido de más información sobre lo artístico, aunque tambien pueda llegar a un usuario virtual que navega la web y la utiliza para estar en contacto con experiencias artísticas sin tener que visitar el espacio físico.

En definitiva, para clarificar lo esgrimido hasta aquí, sostenemos que "ediciones digitales" atiende a la experiencia museal y no solo a su valor en sí mismo. Es decir, sus condiciones de formato, diseño y contenido por señalar solo algunas características- convierten a este tipo de publicación en una herramienta para dar a conocer, a los públicos, un cierto estilo de exposición, determinados artistas y una línea cutoratorial sobre la colección, al mismo tiempo que se reconoce la identidad del museo, tal como si fuera una obra en sí mismo. Estas propuestas son el formato más novedoso que se proyecta en los últimos años en los museos de la ciudad de Rosario (Santa Fe, Argentina), ya que difieren no solo en su constitución y soporte, sino también al convertirse en una amalgama que intenta romper con el simple registro y archivo para aportar nuevos argumentos y visualizaciones sobre el patrimonio; transformándose, de esta manera, en una experiencia portátil en sí misma. 


\section{Palabras finales}

El museo en la contemporaneidad intenta conjugar las lógicas comerciales con la fomentación de condiciones plurales de participación social. Cada recinto, sin perder de vista su rol disciplinador, se adapta a este nuevo orden teniendo presente sus posibilidades contextuales y aspiraciones institucionales. De allí que las publicaciones que realizan se convierten en dispositivos comunicaciones que habilitan nuevos modos posibles de presentación de estas instituciones culturales en la actualidad, a la vez que la representan, ya sea bajo una actitud de simple consumo o al habilitar la reflexión crítica con el otro.

El caso analizado, "ediciones digitales", se presenta como un posible ejemplo sobre estos dilemas. Estamos ante una propuesta -a pesar de las diferencias en sus ediciones- que refleja una política institucional y editorial que innova tanto desde el formato -producto del uso de las TICs-, los contenidos y la estética al romper con estructuras clásicas que se hacen presentes en estos dispositivos comunicacionales. En este sentido, este tipo de propuesta editorial nos lleva a reflexionar sobre la posibilidad de pensar al Museo Castagnino+macro en el camino a convertirse en un museo amplificado; una entidad patrimonial que apela a dispositivos que buscan generar experiencias distintas con los públicos, tal como se espera del ser contemporáneo. Sin embargo, no podemos dar una certeza, ya que las sedes museales siempre están en construcción debido a que la contemporaneidad se están pensando día a día, en la propia dinámica del presente.

\section{Bibliografía}

BAENZA, Federico; DEL RIO, Claudia; TARTAGLIA, Leandro y VILLANUEVA, Santiago. Construcción de un museo. Rosario: Ediciones Castagnino/macro. 2014. Disponible en https://issuu.com/edicionesmuseo/docs/edcm5construccindeunmus. Acesso en: 1 de Octubre de 2018.

BENETT, Tony. The exhibitionary complex. In: GREENBERG, Reesa; FERGUSON, Bruce; NAINE, Sandy (comp.) Thinking about Exhibitions. London: Routledge, pp. 69-92. 1996.

CHIN-TAO, Wu. Privatizar la cultura. Madrid: Akal. 2007.

DEWEY, John. El arte como experiencia. Barcelona: Paidos. 2008.

DOLINKO, Silvia. Impreso en la Argentina. Recorridos de la gráfica social desde la colección del Museo Castagnino+macro. A 50 años del Gran Premio en Grabado a Antonio Berni en la Bienal de Venecia. Rosario: Ediciones Castagnino/macro. 2012. Disponible en https://issuu.com/edicionesmuseo/docs/edcm1. Acesso en: 8 de Septiembre de 2018.

FLAK, John y DIERKING, Lynn. The museum experience. USA. Whalesbeck Books.1992.

GARCIA CANCLINI, Néstor. Culturas Hibridas: estrategias para entrar y salir de la modernidad. Barcelona: Paidos Iberoamerica. 2001.

GUASCH, Ana María y ZULAIKA, Joseba. Aprendiendo del Guggenheim Bilbao. El museo como instrumento cultural. Madrid: Akal. 2007.

GETINO, Octavio. Las industrias culturales en la Argentina. Dimensión económica y políticas públicas. Buenos Aires: Editorial Colihue. 1995.

HAACKE, Hans. Museums, Managers of Consciousness Unfinished Business". New Museum of Contemporary Art y MIT Press, Nueva York y Cambridge MA, pp.60-73. 1986.

HUYSSEN, Andrea. En busca del futuro perdido Cultura y memoria en tiempo de globalización. Buenos Aires: Fondo de Cultura Económica. 2007.

LASECA, Roc. El museo imparable. Sobre institucionalidad genuina y blanda. Chile: Metales Pesados. 2016.

LOPEZ CARABAJAL María Paz y MONTINI, Pablo. París en el horizonte. La colección de Enrique Astengo. Rosario: Ediciones Castagnino/macro. 2016. Disponible en https://issuu.com/edicionesmuseo/docs/edcm6-parsenelhorizonte. Acesso en: 8 de Septiembre de 2018.

LUCERO, María Elena. De azares, sueños y ficciones. Rosario: Ediciones Castagnino/macro. 2011. Disponible en https://issuu.com/edicionesmuseo/docs/edcm2. Acesso en: 8 de Septiembre de 2018. 
MALOSETTI COSTA, Laura; LOPEZ CARABAJAL, María Paz y MONTINI, Pablo. Entre siglos. El impulso cosmopolita en Rosario. Rosario: Ediciones Castagnino/macro. 2012. Disponible en https://issuu.com/edicionesmuseo/docs/edcm4. Acesso en 8 de Septiembre de 2018

PANOZZO ZENERE, Alejandra. Se contempla, se experimenta. Modos de comunicacionar del museo de arte contemporáneo. Rosario: UNR Editora. 2018

PARRA, Diego. Cuahtémoc Medina: Filtraciones criticas para la curaduría Contemporánea. Artichok, Santiago, 2015. Disponible en http://artishockrevista.com/. Acesso en: 8 de Septiembre de 2018.

PEREZ RUIZ, Maya Lorena. La museología participativa: ¿tercera vertiente de la museología mexicana? Cuicuilco, vol.15, n44, México, pp. 87-110. 2008.

PODGORNY, Irina. El sendero del tiempo y de las causas accidentales: los espacios de la prehistoria en la Argentina. Rosario: Prohistoria Ediciones. 2009.

SCOLARI, Carlos. Hipermediaciones. Elementos para una teoría de la Comunicación Digital Interactiva. Barcelona: Gedisa. 2008

SPINELLI, María E. (2012). \#espacio. Rosario: Ediciones Castagnino/macro. Disponible en https://issuu.com/edicionesmuseo/docs/edcm1. Acesso en 8 de Septiembre de 2018.

STRONG, Roy. El museo como vehículo de comunicación. Museum, Paris, año XXXV, n² 2, pp. 75-81. 1993.

VERÓN, Eliseo. Le plus Vieux média du monde. MSCOPE, Paris, № 3. 1992.

\section{Datos de la autora}

\section{Alejandra Panozzo Zenere}

Doctora en Comunicación por la Universidad Nacional de Rosario (Argentina) y Magister en Industrias Culturales Política y Gestión por la Universidad Nacional de Quilmes (Argentina). Licenciada y Profesora en Bellas Artes con especialidad en Teoría y Critica por la Universidad Nacional de Rosario (Argentina). Recibió Beca Doctoral del Consejo Nacional de Investigaciones Científicas y Técnicas (CONICET). Actualmente, realiza su Postdoctorado con Beca del Centro de investigaciones Científicas de Argentina (CONICET). Se desempeña como docente de la Universidad Nacional de Rosario y en la Escuela Municipal de Museología de Rosario.

Autora del libro "Se contempla, se experimenta. Modos de comunicar del museo de arte contemporáneo" (UNR Editora, 2018), editado con el premio del Ministerio de Cultura de la Nación. Además, cuenta con capítulos en libros, publicaciones en revistas científicas y se ha presentado como disertante en diversas Jornadas, Simposios y Congresos nacionales e internacionales en el cruce interdisciplinar del campo de la museología, la comunicación y el arte.

panozzo.a@gmail.com

Received: 2018-02-03

Accepted: 2019-03-15

\section{$(\mathrm{cc})$ BY}

This work is licensed under a Creative Commons Attribution 4.0 United States License.

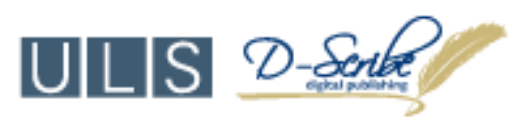

This journal is published by the University Library System of the University of Pittsburgh as part of its D-Scribe Digital Publishing Program and is cosponsored by the University of Pittsburgh Press. 